América sin nombre, n. ${ }^{\circ} 22$ (2017) 83-89

DOI 10.14198/AMESN.2017.22.07

ISSN: 1577.3442 / eISSN: 1989-9831

Fecha de recepción: 30/10/2017

Fecha de aceptación: 13/11/2017
Puede citar este artículo como:

Prado Alvarado, Agustín. "Cuentistas peruanos en busca de lector». El cuento hispanoamericano del siglo XXI. Agustín Prado Alvarado (coordinador). América sin Nombre, 22 (2017): 83-89, DOI: 10.14198/ AMESN.2017.22.07

Link para este artículo: http://dx.doi.org/10.14198/AMESN.2017.221.07

\title{
Cuentistas peruanos en busca de lector
}

\author{
Peruvian storytellers looking for a reader
}

\author{
Agustín Prado Alvarado* \\ Universidad Nacional Mayor de San Marcos
}

\section{Resumen}

El presente texto es una revisión del cuento peruano en los primeros quince años. Se revisará los contextos sociales y culturales donde ha continuado el cultivo del cuento y los nuevos derroteros seguidos por los nuevos escritores del relato breve. Se puede reconocer que hay líneas temáticas como el realismo urbano y el tema de la migración a los que se ha sumado un interés por la literatura fantástica.

Palabras clave: Cuento peruano, realismo urbano, literatura fantástica, lectores

\begin{abstract}
The present text is a review of the Peruvian story in the first fifteen years. We will review the social and cultural contexts where the story has been cultivated and the new paths followed by the new writers of the short story. It can be recognized that there are thematic lines such as urban realism and the subject of migration to which has been added an interest in fantastic literature.
\end{abstract}

Keywords: Peruvian story, urban realism, fantastic literature, readers

Una revisión del cuento peruano publicados de manera individual, en formato de libro o en antologías en los primeros quince ańos del siglo xxi puede permitirnos aseverar que hay una continuada madurez del relato breve que explorará otros formatos que van ampliando los marcos temáticos y estilísticos que ya asomaban en algunos cuentos de los años noventa (y en las décadas pasadas). Estos derroteros nos permiten distinguir relatos que incurren en espacios cosmopolitas, el género fantástico, el formato del cómic, las historias intimistas y privadas, todos estos derroteros no estuvieron ausentes en los años ochenta y noventa, sin embargo, se manifiestan de manera continua en el siglo xxI.

\footnotetext{
* Agustín Prado Alvarado es profesor titular de Literatura Española e Hispanoamericana en la Universidad Nacional Mayor de San Marcos. Ha sido becario de la Agencia Española en la Universidad Autónoma de Barcelona (1997). Realizó estudios de Maestría y Doctorado en Literatura Peruana y Latinoamericana en la Universidad de San Marcos. Ha publicado artículos sobre la obra de Gabriel García Márquez en el suplemento El Dominical de El Comercio y la revista literaria Lucerna. Fue codirector de la revista de literatura Ajos \& Zafiros. Con Sandro Chiri editó el libro Las cartografías del poder en la obra de Mario Vargas Llosa. Ensayos literarios (2014). Ha participado, además, en numerosos congresos y coloquios tanto en el Perú como en España, Brasil, Francia, México, entre otros países.
} 
Históricamente en los primeros quince ańos del siglo Xxi hay un marco social, político y cultural muy contrapuesto a lo ocurrido en los ańos ochenta y la década de los noventa, esta última signada por la dictadura del fujimorismo. Entre las consignas del fujimorismo se proclamaba la estabilidad económica (la solidez de la moneda peruana) y la derrota militar de Sendero Luminoso y el MRTA. El retorno a un sistema democrático en el siglo XxI, lamentablemente, ha venido acompañado por el desenmascaramiento de líderes políticos envueltos en la corrupción, asimismo la estabilidad económica no ha permitido todavía un mejoramiento cabal de la sociedad peruana y las brechas sociales todavía mantienen sus distancias.

Sin embargo, este retorno a la democracia, con cuatro gobiernos elegidos libremente y el impedimento del retorno del fujimorismo están ligados a los nuevos escenarios culturales que permiten comprender la consolidación de espacios para la difusión del cuento: el desarrollo de las editoriales independientes, el mayor acceso de las clases medias a internet, espacios televisivos de difusión de libros, descentralización de actividades como la Feria del Libro que empezó desarrollarse en capitales de provincias como Trujillo, Arequipa y Cuzco, y la creación de la Casa de la Literatura Peruana (institución estatal dedicada exclusivamente a difundir la obra literaria de los escritores/as peruanos tanto los consagrados como aquellas voces menos difundidas)

Consideramos que un primer punto para tomar en cuenta la difusión y promoción del cuento a nivel institucional es la continuación de algunos premios reconocidos (aunque también polémicos) del cuento entre los que destacan el Premio del Cuento de las 2000 palabras promovido por la revista Caretas y el Premio del cuento Copé de Petro Perú, en este último caso la premiación económica está acompañada por la publicación de los cuentos ganadores y de los finalistas.

Para tomarle el pulso al cuento literario peruano de este nuevo siglo; los mejores barómetros son las antologías realizadas sobre este género y como toda antología genera sus reconocimientos y sus rechazos. A nuestro criterio las más significativas son tres: la antología preparada el crítico Ricardo González Vigil para Ediciones Copé de Petro Perú, que además es la más ambiciosa compilación sobre la historia del cuento peruano desde sus orígenes en el siglo XIX, sus antecedentes en la Colonia, y un acierto a reconocerse es la incorporación de la literatura oral muchas veces desatendida por la crítica y los lectores.
El criterio de González Vigil está pautado por el eje temporal de los diez ańos (el primer tomo publicado en 1983 abarcaba de 1971 a 1979).

La última antología, justamente la que se ocupa de los cuentos del siglo Xxi, es la más ambiciosa (son dos volúmenes) y hace conocer a los nuevos escritores quienes han editado sus primeros libros de cuentos al lado de escritoras y autores reconocidos en la comunidad de letrados peruanos, como es el caso de Alfredo Bryce Echenique. Esta antología -que igual siempre ha generado comentarios y rechazoscontiene un prólogo donde González Vigil explica los rasgos que podemos encontrar en estos cuentos.

La segunda antología que comentaremos se titula Selección peruana 2000-2015 que juega con el formato de un equipo de fútbol, el deporte más popular y desbordante. El «director técnico» es Ricardo Sumalavia, un reconocido escritor de cuentos y novela que empezó a publicar en los ańos noventa. Sumalavia que había aparecido en una anterior antología con el mismo nombre Selección peruana, ahora como muchos deportistas reconocidos en este caso como un reconocido escritor es quien se ha encargado de convocar a los jóvenes escritores del siglo XXI: la distinción de este libro es la heterogeneidad de los sexos, hay escritoras y escritores con lo cual se quiebra la mirada homogénea sobre un equipo literario.

Uno de los aspectos positivos, aparte de la selección de cuentos (con los que siempre se podrá discrepar o coincidir) es el cuestionario a los autores(as) del libro. Como lo ha explicado este balotario de preguntas sigue el modelo que Abelardo Oquendo preparó y edito en 1970 en la clásica antología Narrativa peruana 1950-1970) para Alianza Editorial de España. Las respuestas que se recogen al final del libro nos permiten conocer las poéticas literarias de estos escritores/as, aunque hubiese sido interesante añadir una pregunta centrada en el cuento literario. Consideramos que esta apreciada antología nos permite acercarnos a los nuevos cuentos de la literatura peruana en el siglo XXI.

La tercera antología es la que ha preparado Víctor Ruiz Velazco, poeta, editor y un encomiable gestor cultural de la vida literaria limeña. El libro titulado El fin de algo. Antología del nuevo cuento peruano 2001-2015 (2015). Difiere de la edición de Sumalavia en un mayor número de cuentos y coincide en registrar escritores de ambos sexos. Esta antología además cuenta con un prólogo que examina el fenómeno del cuento desde las herramientas de la crítica y la teoría de la literatura. Para Ruiz 
Velazaco la lectura de esta narrativa tiene sus puntos de inicio en la década de los años 90, incluso con algunos textos críticos de los escritores Selenco Vega e Iván Thays. Desde nuestra perspectiva este texto de entrada por su carácter panorámico destaca algunas líneas que deben considerarse para el estudio del cuento como la vertiente fantástica.

Con estas tres antologías podemos empezar a revisar a estos nuevos escritores en busca de lectores, nuevos lectores que han accedido a muchos de estos cuentos por formatos electrónicos, por estas antologías y todavía por el formato libro impreso que continúa teniendo una sitial en la lectura del cuento peruano.

Carlos Yushimito del Valle (Lima, 1977) es uno de los escritores que está trazando uno de los más sólidos derroteros en el género del cuento, sus tres libros de relatos han conseguido un merecido reconocimiento en las comunidades letradas peruanas e hispanoamericanas. Empezó publicando un relato El mago (2004) en la colección peruana Sarita Cartonera, sin embargo, fue su primer libro Las islas (2006) el que obtuvo inmediatamente prestigio entre críticos lectores.

Yushimito, además, como se ha mencionado tiene una formación académica en Literatura en la Universidad Nacional Mayor de San Marcos y en la Universidad de Brown. Para comprender esta relación con la tradición literaria debemos revisar el artículo «Subjetividad oficial: exilios, desintegraciones y otros. Una lectura de la crisis social en la narrativa de Alonso Cueto, Jorge Valenzuela y Guillermo Niño de Guzmán» publicado en el año 2008. En este artículo se hace atinados reparos a la crítica literaria peruana que ha centrado con exclusividad a la narrativa peruana ceńida casi con exclusividad en el tema del conflicto armado interno y ha obviado a los escritores que han desarrollado otras temáticas distantes del tema fetiche de los críticos y de muchos narradores. Yushimito revisa específicamente la obra cuentística de estos escritores (en el caso de Jorge Valenzuela y Guillermo Niño de Guzmán su obra literaria pertenece casi con exclusividad al género del cuento).

Este artículo, además, nos permitiría ir apreciando una poética de Yushimito que se puede ir completando con otros paratextos como las opiniones que ha desarrollado sobre la tradición literaria peruana.

Las islas es un libro hilvanado por ocho cuentos en los cuales el cronotopo nos ubica en escenarios del Brasil. Esta elección de estos espacios rompe con un formato tradicional de los cuentos peruanos mayormente escenificados en territorios urbanos (céntricamente la capital de Lima) o la provincia de la costa, el mundo rural andinos o la imponente y tupida amazonia. Aunque hay escritores como los de Alfredo Bryce Echenique, Julio Ramón Ribeyro, Carlos Eduardo Zavaleta o Alonso Cueto (en su primer libro La batalla del pasado) quienes han escrito cuentos ubicados en ciudades como París, Madrid o alguna ciudad norteamericana lo cual creaba una atmosfera cosmopolita a estas historias, sin embargo, su anclaje con una temática peruana se manifiesta por los personaje (originarios del Perú) o un contexto lingüístico donde el castellano es una marca de identidad o contrapone una temática de desarraigo.

Esto no sucede en los cuentos del libro de Yushimito: las calles, plazas, paisajes rurales y los personajes son brasileños. Se ha destacado la capacidad fabuladora para describir un Brasil imaginario que no proviene de una experiencia real del autor, en ciertas entrevistas Yushimito ha confesado que escribió los ocho cuentos sin todavía haber pisado suelo brasileño (Ezio Neyra, 2007). La capacidad para ambientar estos escenarios brasileńos proviene del adecuado registro lingüístico y una solvencia en el manejo del estilo lo que permite la verosimilitud de las historias. Una de estas estrategias proviene de los nombres de los personajes a quienes un lector hispano(peruano) rápidamente puede reconocer lingüísticamente en portugués: Chico Pires Duarte, Zé Antunes, Pedro de Assis, Luizinho, igualmente los topónimos están mencionados en portugués como se distingue en nombres como rúa Conde de Bonfim, rúa Carvalho, Calçadáo de Matinhos, Serra Talhada, entre otros. Otro registro lingüístico que contribuye a la creación de la atmosfera brasileña son los epígrafes literarios que sirven de antesala a los cuentos y los que están al inicio del primer y último cuento. Efectivamente, los epígrafes iniciales provienen de dos escritores brasileños: el poeta Cassiano Ricardo y el narrador Carlos Drummond de Andrade.

La creación de estos escenarios como elección para el tejido de cada trama supone un distanciamiento de las poéticas del cuento peruano que ha imperado durante el siglo Xx.

Estos ocho cuentos registran historias donde cada personaje está marcado por un signo trágico, procedencia marginal y una épica personal. En el primer cuento del libro «Bossa Nova para Chico Pires Duarte» la historia está ensamblada en diez partes numeradas donde transcurre el relato (esta segmentación numerada será un signo distintivo en otros relatos del libro). Por la temática de esta historia 
podemos apreciar rasgos provenientes de la narrativa negra y policial, el protagonista quien ha cometido un crimen por ajustes sentimentales. El relato tensa la trama mediante una información mediante el uso de analepsis lo cual permite al lector explicar los móviles del crimen.

Otro detalle de este cuento es el carácter oral que se impregna en la historia. Aunque la voz narrativa utilizada para contar esta historia es el tradicional narrador omnisciente (heterodiegético/extradiegético) se revela que uno de los personajes el viejo Eduardo, amigo y confidente de Chico Pires Duarte, es quien se encargará de perennizar la historia de su amigo por medio de una canción de bossa nova.

El segundo relato donde encontramos otra historia de ajuste de cuentas es "Apaga la próxima luz», aquí la voz del narrador muestra su capacidad metaliteraria en la cual indica al lector las posibilidades argumentales para escoger la trama con lo cual se distancia del discurso tradicional del realismo y recupera un tipo de registro de herencia cervantina: el narrador metaliterario que en ciertos pasajes recuerda al lector su testimonio.

Los once cuentos del libro Guerra a la luz de las velas (2006) del escritor Daniel Alarcón (Lima, 1977) escritos primero en inglés y posteriormente traducidos en dos ocasiones al castellano aunque la versión española más difundida ha sido la editada por el sello Alfaguara muestran a un escritor peruano insertado en la cultura norteamericana y que ha optado por la escritura en inglés en la mayoría de sus textos. Este rasgo de la escritura en inglés debemos apreciarlo desde la categoría de heterogeneidad que Antonio Cornejo Polar había defendido como característica de la literatura peruana. Podemos indicar que es un aspecto de una heterogeneidad lingüística que en el caso de Alarcón no es caso aislado, podemos recordar en la tradición peruana a Ventura García Calderón, César Moro o César Vallejo quienes escribieron en francés.

El libro apareció en castellano en el sello Alfaguara el mismo año que se editó Las islas de Carlos Yushimito, aunque sus derroteros literarios tienen evidentes diferencias se puede establecer algunos puntos en común. Primero el giro lingüístico como la opción por otra lengua que no sea el castellano. En el caso de Yushimito con los giros portugueses de sus cuentos y en el caso de Alarcón en lo correspondiente al inglés.

Otro aspecto que encontramos en estos cuentos son los escenarios, por un lado tenemos el mundo andino, Lima y la cosmpolita Nueva York. En los cuentos de Alarcón muy bien podemos inscribirlo en una primera lectura en los registros del realismo urbano, además de registrar uno de los temas que se ha convertido casi en tópico de la literatura peruana: el Conflicto Armado Interno, los Años de la Violencia, la Guerra Interna, o la Época del Terrorismo, diferentes denominaciones para intentar registrar históricamente las acciones genocidas de Sendero Luminoso y El MRTA, a los cuales lamentablemente se sumó el terrorismo del Estado.

El cuento que aborda este tema, uno de los más logrados del libro, «Lima, Perú, 28 de Julio de 1979». El narrador, en primera persona, realiza un recuento de su vida en la época del terrorismo donde el nudo es la primera incursión en un acto de propaganda y la breve interacción que mantiene con un policía. A partir de este suceso el narrador-protagonista realiza un recuento sobre su vida y su incursión en el arte de la plástica, por ello recibe el apelativo de "pintor».

Aunque hay un desarrollo clásico del relato, las analepsis nos permiten observar estos temas recurrentes en la vida del pintor y se aborda los temas de la migración, los desplazamientos del campo a la ciudad y viceversa, igualmente la vida de la familia provinciana en Lima. El personaje además establece una relación de compenetración con la ciudad: «Yo me convertí en una de esas personas. Vi la ciudad y sentí su caos y su energía; ya no podía volver a casa” (108). Esa compenetración con la ciudad muestra una situación distinta del personaje migrante con la capital peruana si comparamos este relato con los cuentos de los años 50 donde los personajes migrantes y marginales (Congrains, Ribeyro, Zavaleta) mostraban esa incapacidad de estos personajes de formar parte de la ciudad.

Los contextos sociales en el relato de Alarcón permiten encontrar otra relación: este personaje ya no tiene ese temor a Lima, la capital es parte de él, se ha insertado en sus instituciones como la universidad y desempeña una actividad artística por la cual es reconocido, el mismo relato afirma esta pertenencia a la ciudad: «He vivido la turbulencia adolescencia de Lima y su crecimiento desmedido. Ahora la ciudad es mía» (108). Esa actitud desafiante no solamente forma parte del protagonista, el relato se concentra en la etapa de militante de Sendero Luminoso.

En el año 2007 se publicó el libro Punto de fuga de Jeremías Gamboa (1975). Un total de ocho cuentos retrataban historias centradas en la ciudad de Lima en barrios de clase media y protagonizados por personajes en la edad juvenil insertados en los mundos universitarios y en los oficios del periodismo le dan 
una cierta unidad a este libro. Nuevamente la capital peruana es el espacio centrípeto en el interés de un escritor como Gamboa, a diferencia de Alarcón que también ubica muchos de sus relatos en Lima, los personajes de Gamboa no se identifican con las problemáticas de los migrantes o provincianos, aunque podemos reconocerlos como hijos de provincianos insertados en otras preocupaciones distantes como el tema del conflicto armado interno, en sus relatos uno de los temas frecuentes es el mundo de la prensa especialmente del mundo de El Comercio.

Esta relación con la ciudad es uno de los puntos que se puede destacar del libro, incluso algunos cuentos mencionan los escenarios que jugarán un rol en los argumentos como sucede en «El edificio la calle Los Pinos» o «Un responso por el cine Colón». En el primer relato encontramos una incursión en una edificación en el barrio de Miraflores, considerado uno de los distritos más elegantes y prósperos de Lima. El cuento empieza creando una intriga inmediata cuando el protagonista- quien asimismo es el narrador del relato- es despertado por uno de sus amigos, Pineda, quien ha venido a buscarlo porque un extraño ha entrado a su edificio en la calle Los Pinos.

Esta intriga permite al narrador reflexionar sobre sus vidas y la relación con la ciudad, los estudios universitarios y la vocación artística en el campo del cine y de la literatura, sin embargo, podemos encontrar en este cuento la mirada sobre la ciudad.

Incluso llegué a sentir algo de envidia al escucharlo: el sitio era amplísimo, lleno de.luz y estaba ubicado en el undécimo piso de un edificio que quedaba a solo una cuadra del parque central de Miraflores. Desde las ventanas de su habitación -recuerdo que me dijo esto con un brillo intenso en los ojos-, se podía ver el mar y el perfil de la ciudad (15).

El relato que empieza creando una intriga de carácter enigmático se traslada a los apuntes biográficos de Pineda detallados por el narrador: los orígenes humildes, la incursión en el mundo de la prensa como fotógrafo en el diario El Comercio y el fortalecimiento de su economía al conseguir un puesto fijo en el periódico. Estos detalles permiten resaltar la incompatibilidad entre Pineda y el edificio en Miraflores donde se ha instalado.

En palabras de Pineda, vivir en ese edificio: «Me gusta despertar y de pronto correr las cortinas y ver la ciudad y más allá el mar. Es como vivir en otro país, como no estar en el Perú» (25-26), sin embargo, este espacio se convierte solamente en un refugio para el descanso, la extrañeza y el temor que va asediando a Pineda es como si este punto de la ciudad, también fuera un punto de fuga para el personaje.

Otro rasgo que Gamboa acentúa en sus cuentos es la relación de los personajes con ciertos espacios de Lima, muchos de estos escenarios en completa decadencia como se lee en el relato «Un responso por el cine Colón».en esta ocasión es el centro de Lima y la historia está escrita como una crónica de la vida de Felipe Castrejón, un gris periodista que intenta ganarse la vida escribiendo notas (que no consigue vender) en una quincenario raquítico, como lo evoca el narrador en primera persona.

En el desarrollo de la trama podemos encontrar la marginalidad compartida entre el narrador y el protagonista Felipe Castrejón, esta condición de vida es reconocida por la voz narrativa: «Quizás Castrejón me daba seguridad, quizás su torpeza me afirmaba de modo complaciente de cara a lo que yo ya sospechaba era mi propia mediocridad, lo poco que en verdad había hecho por mí y por mi vida» (80).

El eje del cuento que se anuncia desde el título es la nota que ofrece escribir Castrejón sobre el cine Colón, un teatro en pleno Centro Histórico de Lima y que con el transcurrir de los años fue alcanzado por la decadencia que avasalló el centro de la capital peruana. El cine Colón para sobrevivir proyectaba películas pornográficas que albergaban a una galería de hombres anónimos marcados por las secuelas de la soledad y la carencia de afectos

Como en el cuento anterior en esta ocasión el narrador comparte las experiencias biográficas de Castrejón, sus estudios en una Unidad Escolar y su carácter marcado por la extrema timidez que lo arrinconaron a los caminos solitarios de su vida en Lima. Aquí funciona una historia dentro de otra, pues Castrijon relata una experiencia estrambótica al contar como se unieron los asiduos visitantes del cine Colón cuando se sintieron estafados en la exhibición de una versión pornográfica de Batman, titulada Las aventuras secretas de Batman y Robin. La historia cargada de hilaridad es uno de los mejores pasajes del cuento en los cuales Castrejón descubre la dimensión arquitectónica del teatro Colón cuando se encienden por primera vez las luces para el público.

Para un lector (in fábula, al decir de Umberto Eco) este cuento tiene un parentesco literario con algunos cuentos de Ribeyro quien ha radiografiado a los «mudos» y marginales de Lima como la vida de Castrejón, aunque no hay ese intento por saltar de esa marginalidad como sucede en el mundo 
Ribeyriano, igualmente el mundo de la prensa con personajes aplastados nos recuerda a Conversación en La Catedral de Mario Vargas Llosa, a quien Jeremías Gamboa siempre ha manifestado una admiración por sus novelas.

Uno de los ejes temáticos que en el siglo Xxi ha ganado un sitio muy visible entre los lectores y un sector de la crítica literaria es el género fantástico y la ciencia ficción. Podemos indicar que hay una suma de factores para este despertar de los fantástico: 1) los trabajos académicos que han pasado de la investigación universitaria al libro editado, aquí destaca especialmente los trabajos y antologías preparados por Elton Honores, asimismo también los trabajos de rescate de figuras como Clemente Palma quien ha sido reeditado (edición de Ricardo Sumalaivia) y de textos de crítica que han revalorado su importancia en el cuento entre los que destacan los textos en revistas como Ajos \& Zafiros y las investigaciones de Moisés Sánchez Franco. 2) Los congresos, coloquios y mesas redondas que, principalmente Elton Honores ha impulsado en los últimos años, muchos de estos eventos tienen sedes reconocidas por el público peruano que asiste asiduamente a la Casa de la Literatura Peruana, el Instituto Raúl Porras Barrenchea y el Centro de Estudios Antonio Cornejo Polar. 3) Las antologías editadas con gran esmero por José Donayre, además el mismo es una notable escritor de cuentos que ha explorado nuevos territorios fuera del realismo, sus antologías entre las que destacan Antología de cuentos peruanos sobre monstruos $(2013,2015)$, Se vende marcianos. Muestra de relatos de ciencia ficción peruana (2015) y Trece veces Sarah (2017) es una muestra del gusto del escritor y de los lectores quienes han respondido favorablemente a estos cuentos.

Del nuevo corpus de libros de cuentos sobre el género fantástico destacaremos el segundo libro de relatos de Yeniva Fernández, Siete paseos por la niebla (2015), el primer libro que Fernández editó Trampas para incautos (2009), todavía estamos ante una escritura que está afinando sus herramientas estilísticas, aunque entre estos relatos apreciamos «Sierra Norte».

Siete paseos por la niebla está conformado por siete cuentos a los que podemos reconocer dentro de los formatos de lo insólito o la categoría (neo)fantástico. Las protagonista de estos relatos son mujeres quienes pertenecen a las esferas de las clases medias, en diversos cuentos es una narradora en primera persona quien revela los acontecimientos sucedidos.

Un aspecto que se disfruta mucho de la narrativa de Yeniva Fernández es su apuesta por el relato clásico donde la intriga envuelve rápidamente la lectura de estos relatos. En el cuento «Rutka o la historia de lagunas flores extrañas» la historia se desplaza en dos escenarios y en dos tiempos: la época de la infancia de la protagonista y el mundo adulto, la estrategia narrativa ha sido el uso del in medias res que permite ir al pasado y retornar al punto de inicio de la narración. En este cuento el personaje de Rutka se convierte en un enigma misterioso quien termina evidenciando su real naturaleza y pertenencia a una estirpe diferente en peligro de extinción.

Otro libro de cuentos del género fantástico es Los condenados (2016) de Moisés Sánchez Franco, quien había publicado algunos de estos relatos en los libros editados por PetroPerú cuando obtuvo en dos ocasiones las menciones honrosas por sus cuentos.

El título Los condenados podría parecer explícito por la resonancia semántica de la palabra, pero justamente ese título es lo primero que puede envolver a un lector con las primeras preguntas: ¿por qué los condenados? ¿Quiénes son los condenados? ¿Por qué están condenados? En mi lectura un título como Los condenados me evoca a los personajes del Infierno de la Comedia del florentino Dante Alighieri con quien este libro puede tender muchos puentes, recordemos que los personajes del poeta italiano están encapsulados en un averno perteneciente al imaginario cristiano.

El imaginario de Sánchez Franco atraviesa diferentes escenarios y discursos y sus condenados pertenecen a diversos estratos sociales, escenarios a los que podríamos denominar cosmopolitas y oscilan edades diferentes. Igualmente los registros de estos cuentos utilizan variados formatos como la epístola o el diario con lo cual se distancia de una narración clásica guiada exclusivamente por un narrador tradicional, aunque en la estructura del cuento clásico Moisés ha escrito relatos en los que maneja con solvencia el desarrollo de una historia aristótelica: principio, nudo y desenlace.

En el primer cuento «Las cartas de Navidad» el escenario se encuentra en los territorios del espacio hogareño, una voz evoca las cartas recibidas por tía Delia en las navidades. El estilo de este cuento tiene una apariencia realista en este relato se registra las peripecias sentimentales de una tía quien es evocada desde la nostalgia, los comentarios a las cartas que van llegando al hogar sirven para construir la vida de la tía Delia y el abandono del hogar para irse a recorrer el mundo.

El segundo cuento es todo un salto a nivel de registro temático "El sirviente de los demonios», 
narrado en primera persona nos muestra a una criatura perteneciente a la galería de los seres fantásticos quien reflexiona acerca de su mundo y su condición minimizada antes sus temibles amos. A partir de este cuento podemos encontrar ciertas lecturas: Dante, Poe o Hoffman.

Los aspectos de lo fantástico se plasman con nitidez en «El hombre que debió vivir en una botella». Justamente el cuento como especie se caracteriza por la capacidad de tensar muy rápidamente su trama, mucho más si empieza en las primeras líneas como ocurre en este caso: «Cuando John Melachton se redujo hasta el tamaño de una pequeña rata y el médico anunció su imposibilidad de encontrar una explicación científica y una cura al extraordinario fenómeno, los habitantes del pueblo entero de St. Giles, llenos de pavor, decidieron reunirse para pensar entre todos una solución a tan terrible mal» (30).

En el relato "Los cuervos» entramos en una historia de venganza, el personaje de Kleint, víctima de la bravura de unos cuervos carniceros quienes desfiguran su rostro, logra escapar de este ataque para trasladarse ante la persona que ha conseguido una justicia poética y que conducirá nuevamente a Kleint ante sus verdugos alados. La brevedad del relato nos permite apreciar la efectividad del cuento manejado por un narrador tradicional quien guía la historia ensamblada con precisión en seis contundentes párrafos en los que está armado este cuento.

Me detendré ahora en los dos últimos cuentos «El diario negro de Perry Loss King» y «El secreto de Adam von Schiedman", que son los cuentos que usan el formato del diario en el primer relato $y$ en el segundo cuento bordea lo que se denomina nouvelle, o novela corta, o cuento largo.

En el primer cuento nos encontramos ante un proceso de doble escritura los acontecimientos ocurridos en la vida del personaje y aquellos que plasma en su diario, en esa doble vertiente de origen cervantino de mezcla de ficción y realidad. El lector se verá arrastrado a ciertos enigmas que se envuelven en frases como «la soga al pie» que acompañan al lector hasta el final del cuento.

El último relato "El secreto de Adam von Schiedman», es la revelación de un secreto que poco a poco va asomando en las páginas de este largo cuento. La tensión en todo relato se muestra en una trama que va desarrollando de manera pausada el enigma que se anuncia desde las primeras páginas.

Este acercamiento a estos cuentistas quienes han buscado lectores en diversos registros, lenguas y estilos permiten reconocer que el cuento ha encontrado nuevos lectores que bordean los diversos temas y estilos de la literatura peruana mucho más fortalecidos en este nuevo siglo xxI donde el reinado del realismo está cediendo su hegemonía ante nuevos derroteros.

\section{Bibliografía}

Alarcon, Daniel. Guerra a la luz de las velas. Lima: Alfaguara, 2005.

Fernández, Yeniva. Siete paseos por la niebla. Lima: Campo Letrado, 2015.

Gamboa, Jeremías. Punto de fuga. Lima: Alfaguara, 2007. GonZÁlez VigIL, Ricardo. El cuento peruano 2001-2010. Lima: Ediciones Cope. I y II. 2013.

Martínez Gómez, Juana «El cuento peruano del siglo xx en perspectiva» Inti: Revista de literatura hispánica: No. 81-82, (2015): 301-343.

Neyra, Ezio. https://elcomercio.pe/EdicionImpresa/ Html/2007-02-25/ImEcDominical0678055. html (sobre Carlos Yushimito)

Poláková, Dora. «El gran género pequeño. Reflexiones sobre el cuento hispanoamericano». Encuentro de hispanistas. Alchazidu, Athena - Stehlík, Petr (eds.). Brno: Masarykova univerzita, 2012: 89-96.

Ruiz Velazco, Víctor. El fin de algo. Antología del nuevo cuento peruano 2001-2015. Lima: Santuario Editorial, (2015).

SÁnchez Franco, Moisés. Los condenados. Lima: Agalma Editores, (2016).

Sumalavia, Ricardo (Editor) Selección peruana. Lima: Estruendomudo, (2015).

Yushimito, Carlos. Las islas. Lima: SIC Editores, (2001)

http://www.elcultural.com/revista/letras/Punto-defuga/34895

http://www.letras.mysite.com/da241006.htm (sobre Daniel Alarcón) 